\title{
A FORMAÇÃO INICIAL DO PROFESSOR DE LÍNGUA MATERNA: MAPEAMENTO DOS CURRÍCULOS DOS CURSOS DE GRADUAÇÃO EM LETRAS DAS INSTITUIÇÕES DE MINAS GERAIS ${ }^{1}$
}

\author{
THE INITIAL TRAINING OF THE NATIVE LANGUAGE TEACHER: MAPPING OF \\ UNDERGRADUATE CURRICULA OF GRADUATE SCHOOLS OF ARTS AND \\ HUMANITIES IN MINAS GERAIS STATE, BRAZIL
}

\author{
OLIVEIRA, Fabiana \\ fabiana.oliveiraunifal@gmail.com \\ Universidade Federal de Alfenas - UNIFAL-MG \\ EUFRÁSIO, Daniela A. \\ danielaeufrasio@yahoo.com.br \\ Universidade Federal de Alfenas - UNIFAL-MG \\ TORRES, Maria Emilia A. da C. \\ almeidadacruz.mariaemilia@gmail.com \\ Universidade Federal de Alfenas - UNIFAL-MG
}

\begin{abstract}
RESUMO O objetivo do presente artigo é mapear os diversos elementos que configuram o componente curricular "Metodologia do Ensino de Língua Portuguesa" $(M E L P)$ em dez instituições de ensino superior de Minas Gerais, a partir da análise de currículos dos cursos de Letras voltados às licenciaturas para a formação do professor de língua materna. A metodologia adotada para a execução desta pesquisa fundamentou-se na análise de currículos e de programas relacionados ao curso supracitado. Sendo assim, tratou-se, portanto, de uma investigação que se baseou na análise de documentos. A análise dos dados encontrados leva a afirmar a existência de diferentes modos de organização de MELP, que se relacionam aos objetivos dos seus programas de ensino, bem como as suas cargas horárias, dificultando o delineamento de uma base integrada na formação desse futuro professor em nível nacional.
\end{abstract}

PALAVRAS-CHAVE: Currículos. Língua Portuguesa. Licenciaturas

\footnotetext{
${ }^{1}$ Artigo realizado a partir de um recorte de uma pesquisa mais ampla denominada "Disciplinas da Licenciatura voltadas para o ensino de Língua Portuguesa: cooperação acadêmica entre UNIFAL-MG e USP", com o financiamento da FAPEMIG.
} 
ABSTRACT The purpose of this article is to map the various elements that make up the curriculum component "Methodology of Teaching Portuguese Language" (MELP) in ten higher education institutions of Minas Gerais, from the analysis of the curricula of Letters directed to the undergraduate teacher training for language. The methodology adopted for the implementation of this research was based on analysis of curricula and programs related to the course above. Thus, it was, therefore, an investigation that relied on an analysis of documents. Data analysis found leads us to affirm the existence of different modes of organization MELP, which relate to the objectives of its educational programs, as well as their course loads, making the design of an integrated basis in training future teachers that nationally.

KEYWORDS: Curriculum. Portuguese. Undergraduate Degrees.

\section{INTRODUÇÃO}

O objetivo do presente artigo é mapear os elementos que configuram o componente curricular "Metodologia do Ensino de Língua Portuguesa" (MELP) nas instituições de ensino superior de Minas Gerais, a partir da análise dos currículos dos cursos de Letras.

Esclarecemos, de antemão, que na análise documental efetivada, foram encontradas distintas denominações, tais como: "Estágio Supervisionado de Língua Portuguesa", "Estágio Curricular Supervisionado", "Planejamento e Orientações de Práticas de Ensino em Língua portuguesa", dentre outras. Contudo, a fim de evitar esta dispersão denominativa, no corpo do presente artigo, a referência aos componentes curriculares voltados para métodos e estágio em ensino de Língua Portuguesa dá-se somente pela designação "Metodologia do Ensino de Língua Portuguesa" e pela sigla MELP. Nos quadros apresentados, no decorrer deste texto, serão esclarecidas todas as nomenclaturas identificadas.

As ponderações realizadas a respeito do trabalho em MELP levaram-nos, no decorrer do trabalho investigativo, a assumir a necessidade de pesquisar a existência de aspectos curriculares comuns a ponto de configurar uma uniformidade em MELP que fosse passível de ser compartilhada, em especial, se contrapostas a demais caracterizações curriculares que the fossem estranhas, externas, alheias ao limite que garantiria um contorno ao que vem se fazendo na formação do professor de Língua Portuguesa em nosso país. 
Por esse motivo, visamos a: i) questionar a especificidade de seu objeto, ou, ao menos, sobre a existência, em seu interior, de um domínio de objetos; e ii) avaliar se MELP configura-se como uma "disciplina" no sentido foucaultiano.

Nesse sentido, o trabalho investigativo consiste em caracterizar as relações polêmicas que constituem processos internos e externos de delimitação. Além das diferenças quanto a denominações e inserções curriculares, os questionamentos sobre MELP se fazem também em relação à sua carga horária, ao momento do curso em que deve ser oferecida (nos momentos iniciais, nos momentos finais, ao longo do curso) e às relações que estabelece com determinadas áreas e com conhecimentos específicos.

Discute-se, assim, sobre a necessidade de investigar as consequências das escolhas realizadas pelos formadores na futura prática profissional do professor de Língua Portuguesa. Para tal fim, no que segue, visamos a circunscrever o estado atual do estudo que elucida a problemática à qual se voltou a presente pesquisa, que se apresenta como parte dos resultados alcançados no desenvolvimento do Projeto de Pesquisa "Disciplinas da Licenciatura voltadas para o ensino de Língua Portuguesa: cooperação acadêmica entre UNIFAL-MG e USP”.

Com a expansão do ensino universitário, em nosso país, cada vez mais os pesquisadores serão chamados para pensarem, debaterem e proporem diferentes modos de lidar com as questões que emergem em nossa sociedade. Quanto ao ensino de Língua Portuguesa, este panorama pode claramente ser percebido desde a década de 70 . Nesse sentido, procura-se contribuir refletindo sobre alguns dos avanços e das estagnações que, neste novo século, apontam para o que seja ensinar, atualmente, língua materna.

Este viés investigativo, em que se focalizará o delineamento de características sobre como tem sido balizada e concretizada a formação do professor de Língua Portuguesa no Estado de Minas Gerais, poderá colaborar para que as pesquisas que se voltam para a coleta e análise de dados advindos das escolas mineiras de ensino básico tenham, nos resultados alcançados pela presente proposta de pesquisa, um referencial importante sobre o recorte teóricometodológico que tem aparecido como subjacente à formação acadêmica dos professores que atuam no Ensino Fundamental e Médio. Dada a relevância de haver aprofundamento das pesquisas a respeito da situação do ensino de língua materna, 
esta proposta justifica-se por somar-se à iniciativa de delineamento da formação inicial do professor de Língua Portuguesa.

\section{O ENSINO DE LÍNGUA PORTUGUESA EM FOCO}

A atual situação da formação de professores no Brasil encontra-se num percurso histórico que começou a delinear-se na década de 70 do século passado e se constituiu plenamente em meados da década de 80 desse mesmo século, num processo que envolveu a Linguística como um de seus fatores fundamentais (BARZOTTO; BONFIM; SAMPAIO, 2008).

Em face dos grandes contingentes que passaram a frequentar os bancos escolares no momento em que a educação foi colocada, pelo regime militar, a serviço do desenvolvimento, os linguistas, em especial, mas não exclusivamente, passaram a propor mudanças no ensino de Língua Portuguesa a fim de torná-lo mais democrático, menos discriminatório e mais eficiente (BARZOTTO; BONFIM; SAMPAIO, 2008).

A discussão quanto a se ensinar ou não gramática, quanto à necessidade de desfazer as condições em que emerge o preconceito linguístico, quanto a se fazer da escola um espaço transformador da realidade social por meio do respeito pela linguagem do aluno, o que possibilitaria levá-lo a se apropriar da variedade social de prestígio, são debates que se fortaleceram, no Brasil, no período citado e resultaram na produção e publicação de documentos por Universidades e órgãos governamentais responsáveis pela Educação e também por linguistas envolvidos com a questão do ensino de Língua Portuguesa.

Antes da década de 70 , as escolas se limitavam ao ensino de gramática ensinando por meio de imposições de normas altamente prescritivas e algumas extremamente literárias. A gramática imposta era a gramática normativa.

O período de 1970 propôs o trabalho com a linguagem na escola com enfoque voltado para a modalidade oral e escrita. O objetivo seria, então, favorecer a capacidade de comunicação do aluno para sua inserção social, principalmente no campo do trabalho. Neste cenário, o ensino da gramática nas aulas de Língua Portuguesa mantinha-se, contudo, como primordial. 
Nos anos finais da década de 70, tornaram-se frequentes as discussões quanto aos modos de a Linguística auxiliar na melhoria do ensino. As primeiras ocorrências dessas discussões podem ser observadas em documentos como os que compõem os primeiros Boletins da Associação Brasileira de Linguística (ABRALIN). Esses boletins foram publicados no período de 1981 a 1983 e trazem as discussões a respeito da constituição da Linguística como ciência no país, seja em relação a seus aspectos teórico-metodológicos, seja em relação a seu envolvimento com questões sociais e políticas, dentre elas, principalmente as referentes às questões pedagógicas (BARZOTTO; BONFIM; SAMPAIO, 2008).

A década de 80 evidenciou que, mesmo com os avanços da Linguística e dos trabalhos divulgados no Brasil sobre o ensino de Língua Portuguesa, a gramática como foco de ensino, entendida como conjunto de nomenclaturas e um exercício de classificação, persistia ocupando um espaço muito grande no ensino da Língua Portuguesa. Contudo, os debates acerca de um ensino de Língua Portuguesa que não fosse restrito ao ensino de gramática normativa aumentavam nos centros de ensino e pesquisa.

Neste contexto, um debate que considere as novas propostas de ensino de língua bem como as condições de produção dos discursos subjacentes a tais proposições torna-se muito importante. Um dos vieses defendidos para o ensino de Língua Portuguesa propõe, a partir das pesquisas sociolinguísticas, uma concepção de língua que não se restrinja a considerar uma variedade linguística como a única considerada boa, correta, com base na qual se julgam como erradas, pobres, as demais variedades linguísticas. (RIOLFI et al., 2010)

Na década de 80 do século passado, a ênfase foi colocada no professor como fator de mudança do ensino de Língua Portuguesa (GERALDI; SILVA; FIAD, 1996), porém, a realidade observada nas escolas básicas mostrou que os resultados práticos obtidos foram relativamente modestos (RIOLFI et al., 2010).

Por esse motivo, entre outros, o Projeto de Pesquisa "Disciplinas da Licenciatura voltadas para o ensino de Língua Portuguesa: cooperação acadêmica entre UNIFAL-MG e USP", do qual o presente artigo é um de seus resultados, julgou crucial estudar, a partir da ótica de seu formador, inserido nas instâncias universitárias, o perfil de professor de Língua Portuguesa que, atualmente, vem sendo formado nos cursos de licenciatura em Letras. Para tanto, coloca-se a 
seguinte questão de pesquisa: a partir das mudanças educacionais que se instituíram no ensino de Língua Portuguesa na década de 90, como, no âmbito da $M E L P$, tem se dado a formação do professor de língua materna?

\section{METODOLOGIA DA PESQUISA}

A metodologia adotada para a execução desta pesquisa fundamenta-se na linha de análise de currículos e de programas de cursos de Letras de universidades do Estado de Minas Gerais. Trata-se, pois, de uma investigação que se desenvolve sobre a análise de documentos.

Os dados relacionados aos documentos foram divididos em três categorias de análise retiradas dos termos-chave que foram sendo encontrados ao longo da exploração dos documentos. De acordo com Gomes (1994, p.70), "as categorias são empregadas para se estabelecer classificações [...] trabalhar com elas significa agrupar ideias, elementos ou expresses em torno de um conceito capaz de abranger tudo isso".

As três categorias de análise foram as seguintes: componentes curriculares de conteúdos específicos e metodologias; componentes curriculares associados ao estágio e temáticas presentes nas ementas e nos programas.

A partir disso, organizamos o material por meio de leituras e fichamentos. Esses fichamentos contêm os apontamentos dos termos-chave que foram sendo encontrados nos documentos, pois havia a recorrência de determinados assuntos que se relacionavam.

Os termos-chave estabelecidos foram criados a partir de um princípio único de classificação por meio dos assuntos recorrentes nos documentos, sendo que no conjunto todos os princípios e artigos foram incluídos, mas considerando que nenhum artigo ou princípio fosse colocado em mais de uma categoria.

A partir das análises categorizadas desse modo, apresentadas nos quadros que seguem, pudemos abordar a concepção de "disciplina" para Foucault (2004). Ressaltamos que, para esse autor, uma "disciplina" não se limita à identidade denominativa, mas se refere a uma configuração discursiva em que existe um rol de objetos de estudo, de proposições, de métodos, que se mantém igual mesmo quando existe uma aparente variedade no modo como ele é linguisticamente 
materializado. Por isso, esse autor irá tomar a "disciplina" como uma forma de coerção do discurso, pois ela exige que os seus partícipes produzam a partir de um mesmo conjunto de "verdades". Sobre isso, Foucault (2004, p. 34-5) cita o caso de Mendel, que, para os saberes da Biologia de sua época, não poderia ser considerado um integrante dessa disciplina:

\begin{abstract}
Muitas vezes se perguntou como os botânicos ou os biólogos do século XIX puderam não ver que o que Mendel dizia era verdade. Acontece que Mendel falava de objetos, empregava métodos, situava-se num horizonte teórico estranhos à biologia de sua época. Sem dúvida Naudin, antes dele, sustentara a tese de que os traços hereditários eram descontínuos; entretanto, embora esse princípio fosse novo ou estranho, podia fazer parte - ao menos a título de enigma - do discurso biológico. Mendel, entretanto, constitui o traço hereditário como objeto biológico absolutamente novo, graças a uma filtragem que jamais havia sido utilizada até então: ele o destaca da espécie e também do sexo que o transmite; e o domínio onde o observa é a série indefinidamente aberta das gerações na qual o traço hereditário aparece segundo regularidades estatísticas. Novo objeto que pede novos instrumentos conceituais e novos fundamentos teóricos. Mendel dizia a verdade, mas não estava 'no verdadeiro' do discurso biológico de sua época [...].
\end{abstract}

No que tange a presente pesquisa, verificamos que o inverso também é possível. Ou seja, avaliamos que o fato de haver, nos documentos que analisamos, uma mesma forma de denominação, isso não significa concomitância conceptual, como abordaremos na próxima seção.

\title{
4 A FORMAÇÃO DO PROFESSOR DE LÍNGUA MATERNA: ANÁLISE DOS CURRÍCULOS DOS CURSOS DE LETRAS
}

Foram analisados os currículos de dez instituições de ensino superior de Minas Gerais que possuem o curso de Letras. A análise se deu especificamente a partir das ementas e dos programas de "Metodologia do Ensino de Língua Portuguesa" (MELP), oferecida nesses cursos. As dez instituições serão denominadas nesta pesquisa de IES 1 até IES 10.

Dentre as instituições pesquisadas, há algumas que oferecem o curso de Letras em dois turnos: diurno e noturno, mas a maioria possui uma única oferta no período noturno. Considerando as instituições públicas mineiras de ensino superior em sua totalidade, apenas três não possuem o curso supracitado. 
O quadro a seguir (Quadro 1) apresenta os componentes curriculares de conteúdos específicos e de metodologia para o ensino da língua materna. Essa separação foi realizada, pois algumas instituições que poderão ser verificadas no quadro 2, possuem esse componente agregado ao estágio.

Em sua grande maioria, MELP é ofertada a partir do $6^{\circ}$ semestre. Como alertado anteriormente, há grande variedade denominativa, ainda que, no presente texto, tenhamos adotado uma única sigla de referência ao componente curricular em questão. A ocorrência de $M E L P$ no semestre indicado aponta para algumas concepções relacionadas ao momento em que esse componente é ofertado, sendo primeiramente oferecida a formação voltada aos saberes específicos, à teoria e somente depois o estágio, ou seja, a parte prática, como pode ser verificada abaixo.

Quadro 1: Componentes Curriculares que não agregam o estágio à $M E L P$

\begin{tabular}{|c|c|c|c|}
\hline $\begin{array}{l}\text { Componentes } \\
\text { Curriculares de } \\
\text { conteúdos específicos } \\
\text { e metodologias }\end{array}$ & Carga horária & Semestre & IES \\
\hline---- & --- & --- & IES 1 \\
\hline--- & --- & --- & IES 2 \\
\hline $\begin{array}{l}\text { Saberes Escolares da } \\
\text { Língua Portuguesa; } \\
\text { Metodologia do Ensino } \\
\text { de Português }\end{array}$ & $60 / 60$ & $\begin{array}{l}5^{\circ} ; 6^{\circ} \text { (diurno); } \\
6^{\circ} ; 7^{\circ} \text { (noturno) }\end{array}$ & IES 3 \\
\hline---- & --- & --- & IES 4 \\
\hline $\begin{array}{l}\text { Fundamentos } \\
\text { Metodológicos do } \\
\text { Ensino de Português }\end{array}$ & 60 & $6^{\circ}$ & IES 5 \\
\hline--- & --- & --- & IES 6 \\
\hline--- & --- & --- & IES 7 \\
\hline $\begin{array}{l}\text { Planejamento e } \\
\text { Orientações de Prática } \\
\text { de Ensino em Língua }\end{array}$ & $15 / 15$ & $3^{\circ} ; 4^{\circ}$ & IES 8 \\
\hline
\end{tabular}




\begin{tabular}{|l|l|l|l|}
\hline Portuguesa I e II & & & \\
\hline $\begin{array}{l}\text { Metodologia de ensino } \\
\text { da Língua Portuguesa } \\
\text { em diferentes } \\
\text { contextos; }\end{array}$ & $45 / 15 ; 45 / 15$ & $4^{\circ} ; 6^{\circ}$ & IES 9 \\
$\begin{array}{l}\text { Metodologia de Ensino } \\
\text { de Língua Portuguesa }\end{array}$ & & & \\
\hline--- & --- & -- & \\
\hline
\end{tabular}

Fonte: Ementas analisadas das dez instituições de ensino superior do Sul de Minas.

O quadro 2 (próximo quadro) nos apresenta uma visão geral dos componentes curriculares de ensino de Língua Portuguesa vinculadas ao estágio, que são ofertados geralmente a partir do $6^{\circ}$ semestre, sendo que há quatro instituições que possuem somente esses componentes, responsáveis pelo estágio bem como pela discussão da metodologia do ensino da língua, como pode ser verificado no quadro abaixo. É uma organização que difere das demais e cabe uma reflexão: a junção entre teoria e prática, mesmo que ao final do curso, seria mais impactante para a formação do professor de língua materna.

Quadro 2 - MELP associadas ao Estágio

\begin{tabular}{|l|l|l|l|}
\hline $\begin{array}{l}\text { Componentes } \\
\text { Curriculares associados } \\
\text { ao estágio }\end{array}$ & Carga horária & Semestre & Instituição/Sigla \\
\hline $\begin{array}{l}\text { Prática de Formação/ } \\
\text { Estágio Supervisionado } \\
\text { I, II, III, IV (quatro } \\
\text { componentes que } \\
\text { levam o mesmo nome) } \\
\text { - mesmas ementas }\end{array}$ & $\begin{array}{l}\text { (respectivamente } \\
\text { aos períodos } \\
\text { apresentados a } \\
\text { seguir) }\end{array}$ & $5^{\circ}, 6^{\circ}, 7^{\circ}, 8^{\circ}$ & IES 1 \\
\hline $\begin{array}{l}\text { Laboratório de Ensino I, } \\
\text { II e III (teoria e estágio) } \\
\text { - mesmas ementas }\end{array}$ & $60 / 30 ; 60 / 30 ; 60 / 110$ & $7^{\circ} ; 8^{\circ} ; 9^{\circ}$ & IES 2 \\
\hline $\begin{array}{l}\text { Reflexões sobre } \\
\text { Atuação em espaços } \\
\text { educacionais em Língua }\end{array}$ & $150 ; 150$ & $7^{\circ} ; 8^{\circ} ; 9^{\circ} ;$ & IES 3 \\
\hline
\end{tabular}




\begin{tabular}{|l|l|l|l|}
\hline $\begin{array}{l}\text { Portuguesa I/ Estágio } \\
\text { Supervisionado I e II }\end{array}$ & & \\
\hline $\begin{array}{l}\text { Estágio Supervisionado } \\
\text { em Língua Portuguesa } \\
\text { I, II, III e IV }\end{array}$ & $51 ; 51 ; 51 ; 51$ & $5^{\circ} ; 6^{\circ} ; 7^{0} ; 8^{\circ}$ & IES 4 \\
\hline $\begin{array}{l}\text { Análise da Prática e } \\
\text { Estágio de Português I } \\
\text { e II }\end{array}$ & $60 / 150 ; 60 / 150$ & $8^{\circ} ; 9^{\circ}$ & \\
\hline $\begin{array}{l}\text { Língua Portuguesa: } \\
\text { Estágio Supervisionado } \\
\text { I, II, III e IV }\end{array}$ & $105 ; 105 ; 105 ; 105$ & $5^{\circ} ; 6^{\circ} ; 7^{\circ} ; 8^{\circ}$ & IES 6 \\
\hline $\begin{array}{l}\text { Estágio Curricular } \\
\text { Supervisionado I e II } \\
\text { (Ensino de Gramática e } \\
\text { Prática de Leitura) }\end{array}$ & $30 / 40 ; 30 / 40$ & $6^{\circ}$ & \\
\hline $\begin{array}{l}\text { Planejamento e } \\
\text { Orientações de Estágio } \\
\text { Supervisionado em } \\
\text { Língua Portuguesa I e II }\end{array}$ & $150 ; 150$ & $5^{\circ} ; 6^{\circ}$ & IES 7 \\
\hline $\begin{array}{l}\text { Estágio Supervisionado } \\
\text { de Língua Portuguesa I } \\
\text { e II }\end{array}$ & $15 / 60 ; 30 / 60$ & $7^{\circ} ; 8^{\circ}$ & IES 10 \\
\hline $\begin{array}{l}\text { Estágio Supervisionado } \\
\text { de Língua Portuguesa I } \\
\text { e II }\end{array}$ & $120 ; 120$ & IES 9 \\
\hline
\end{tabular}

Fonte: Ementas analisadas das dez instituições de ensino superior do Sul de Minas.

A presença da parte prática somente no final do curso cria uma compartimentalização dos conhecimentos, produzindo a compreensão de que a teoria está na sala de aula e a prática está fora da sala de aula como dois momentos estanques. Essa perspectiva vai ao encontro da racionalidade técnica tão debatida nos cursos de formação de professores, visando apresentar métodos e técnicas como meios eficientes para se ensinar e separando em dois pólos opostos a teoria e a prática. Neste contexto, a atividade do professor é vista somente a partir de seu caráter utilitário, técnico, de aplicador de fórmulas, retirando de sua prática a reflexão, a investigação e a dimensão política de seu trabalho.

De acordo com Gimeno Sacristán e Pérez-Gomez (1998, p. 357): 
[...] o docente, nessa perspectiva, é um técnico que deve aprender conhecimentos e desenvolver competências e atitudes adequadas a sua intervenção prática, apoiando-se no conhecimento que os cientistas básicos e aplicados elaboraram, ou seja, não necessita chegar ao conhecimento científico, mas dominar as rotinas de intervenção técnica que se derivam daquele.

Nesse sentido, estamos compreendendo que essa compartimentalização é desfavorável à construção do conhecimento pelo aluno que está sendo formado, mas também precisamos considerar que é essencial que inicialmente este tenha conhecimentos necessários para se constituir como um cidadão que seja capaz de tecer reflexões sobre a língua, sobre seus usos e suas variações contextuais e que Ihe auxiliarão nas atividades que a prática do estágio virá a lhe requerer.

A partir do quadro 3, buscou-se apresentar de forma compacta as principais discussões das temáticas presentes nas ementas e nos programas dos componentes curriculares analisados. Verificou-se uma preocupação com a discussão sobre conceitos próprios aos estudos da linguagem, como "língua", "discurso", "leitura", "escrita" e "variação linguística", e outros que denotam a interface entre linguagem e educação, presente em abordagens voltadas para metodologias de ensino, material didático e práticas de ensino. Pelos programas, foi possível verificar uma preocupação a partir dos novos pressupostos para a área de Língua Portuguesa, decorrentes das mudanças paradigmáticas no campo da Linguística, em especial quanto à Sociolínguística.

Quadro 3 - Temáticas centrais encontradas nas ementas

\begin{tabular}{|l|l|l|}
\hline Componentes Curriculares & $\begin{array}{l}\text { Temáticas centrais presentes } \\
\text { nas ementas }\end{array}$ & Instituição/Sigla \\
\hline $\begin{array}{l}\text { Prática de Formação/ Estágio } \\
\text { Supervisionado I, II, III, IV }\end{array}$ & $\begin{array}{l}\text { As ementas não foram } \\
\text { disponibilizadas }\end{array}$ & IES 1 \\
\hline $\begin{array}{l}\text { Laboratório de Ensino I, II e } \\
\text { III Linguagem; Livro Didático; }\end{array}$ & IES 2 \\
\hline $\begin{array}{l}\text { Saberes Escolares da Língua } \\
\text { Portuguesa; }\end{array}$ & $\begin{array}{l}\text { PCN; Competência } \\
\text { Metodologia do Ensino de } \\
\begin{array}{l}\text { Português; } \\
\text { Reflexões sobre Atuação em } 3 \\
\text { espaços educacionais em }\end{array}\end{array}$ & $\begin{array}{l}\text { Metodologias; } \\
\text { Escrita; Literatura }\end{array}$ \\
\end{tabular}




\begin{tabular}{|c|c|c|}
\hline $\begin{array}{l}\text { Língua Portuguesa I/ Estágio } \\
\text { Supervisionado I e II }\end{array}$ & & \\
\hline $\begin{array}{l}\text { Estágio Supervisionado em } \\
\text { Língua Portuguesa I, II, III e } \\
\text { IV }\end{array}$ & $\begin{array}{l}\text { As ementas não foram } \\
\text { disponibilizadas }\end{array}$ & IES 4 \\
\hline $\begin{array}{l}\text { Fundamentos Metodológicos } \\
\text { do Ensino de Português; } \\
\text { Análise da Prática e Estágio } \\
\text { de Português I e II }\end{array}$ & $\begin{array}{lr}\text { Leitura; Escrita; } & \text { Oralidade; } \\
\text { Texto; } \quad \text { Normas } & \text { culta; } \\
\text { Gramática; } & \text { Variação } \\
\text { Linguística; } & \text { Literatura; } \\
\text { Metodologia } & \end{array}$ & IES 5 \\
\hline $\begin{array}{l}\text { Língua Portuguesa: Estágio } \\
\text { Supervisionado I, II, III e IV }\end{array}$ & $\begin{array}{l}\text { Metodologias; Práticas de } \\
\text { ensino; Material Didático; } \\
\text { Teorias de ensino- } \\
\text { aprendizagem }\end{array}$ & IES 6 \\
\hline $\begin{array}{ll}\text { Estágio } & \text { Curricular } \\
\text { Supervisionado I e II (Ensino } \\
\text { de Gramática e Prática de } \\
\text { Leitura) }\end{array}$ & $\begin{array}{l}\text { Gramática; Linguística; } \\
\text { Discurso; PCN; Leitura; } \\
\text { Escrita; Literatura; Análise do } \\
\text { discurso; Prática }\end{array}$ & IES 7 \\
\hline $\begin{array}{l}\text { Planejamento e Orientações } \\
\text { de Prática de Ensino em } \\
\text { Língua Portuguesa I e II; } \\
\text { Planejamento e Orientações } \\
\text { de Estágio Supervisionado } \\
\text { em Língua Portuguesa I e II }\end{array}$ & $\begin{array}{l}\text { PCN; Prática; Descritores de } \\
\text { LP do SAEB; Matriz do } \\
\text { ENEM; Projetos }\end{array}$ & IES 8 \\
\hline $\begin{array}{l}\text { Metodologia de ensino da } \\
\text { Língua Portuguesa em } \\
\text { diferentes contextos; } \\
\text { Metodologia de Ensino de } \\
\text { Língua Portuguesa; } \\
\text { Estágio Supervisionado de } \\
\text { Língua Portuguesa I e II }\end{array}$ & $\begin{array}{lr}\text { Português instrumental } \mathrm{e} \\
\text { como língua } & \text { estrangeira; } \\
\text { Metodologias; } & \text { Práticas; } \\
\text { Leitura; Escrita; } & \text { Gramática; } \\
\text { Morfossintaxe; } & \text { Léxico; } \\
\text { Fonologia } & \end{array}$ & IES 9 \\
\hline $\begin{array}{l}\text { Estágio Supervisionado de } \\
\text { Língua Portuguesa I e II }\end{array}$ & $\begin{array}{l}\text { As ementas não foram } \\
\text { disponibilizadas }\end{array}$ & IES 10 \\
\hline
\end{tabular}

Fonte: Ementas analisadas das dez instituições de ensino superior do Sul de Minas.

A utilização dos documentos oficiais como Parâmetros Curriculares Nacionais de Língua Portuguesa, bem como as avaliações externas oficiais do Sistema de Avaliação da Educação Básica também foram considerados. Além disso, aparece 
também o ensino materializado em enfoques metodológicos, bem como os conteúdos específicos da área, como Fonologia, Léxico, Gramática, etc.

Nas ementas aparece um conceito de "letramento", no entanto, esse conceito pode indicar uma heterogeneidade de concepções, que se dispersam entre os conteúdos elencados nos documentos de cada instituição analisada ${ }^{2}$.

A partir do que ficou registrado no quadro 3, chamou-nos a atenção que as recorrências, localizadas nos documentos analisados, mantinham-se no nível designativo, mas não compareciam em outros aspectos firmados pelos currículos e programas. Isso significa que, apesar de tais documentos fazerem referência a um mesmo espectro de objetos de estudo, tais como "língua", "leitura", "escrita", "letramento", não traziam similaridades teórico-metodológicas suficientes para que pudéssemos afirmar que em MELP localizamos um mesmo "conjunto de verdades", ou seja, que ela se constituiria como uma "disciplina", no sentido foucaultiano.

Por isso, nosso cuidado, no decorrer deste texto, em não nos referirmos a MELP por meio do termo "disciplina", pois como se vê, para o âmbito desta pesquisa, ele não é indiferente. Uma avaliação como esta dos resultados apresentados, neste artigo, leva-nos a duas ponderações.

Em primeiro lugar, ressaltamos o fato de que, apesar de todos os documentos dos cursos de Letras analisados elencarem a formação do professor de Língua Portuguesa em $M E L P$, isso não pode ser confundido com a existência de uma base integrada de caráter "disciplinar". Se, por um lado, isso pode parecer positivo, pois demonstra que os conhecimentos em questão ainda têm algum espaço para a polêmica, por outro lado, pode servir para esconder uma realidade muito controversa, na formação desse profissional, tendo em vista a homogeneidade denominativa. Do que se decorreria reflexões apressadas que poderiam levar a conclusões de que o ensino de "leitura" e "escrita" está resolvido no ensino de Língua Portuguesa, porque estes são conceitos estudados de forma abrangente nos cursos de formação inicial.

A questão que continua é, tendo em vista o histórico de ensino de Língua Portuguesa, do qual apresentamos anteriormente, breve retomada, quais são os conhecimentos sobre "leitura" e "escrita", por exemplo, já superados de acordo como

\footnotetext{
${ }^{2}$ Entende-se por heterogeneidade de concepções a compreensão de que o letramento, por ser um fenômeno social, pode indicar mais de um modelo, por isso, pode-se falar em letramentos, pois eles se referem aos usos contextuais da escrita.
} 
os avanços historicamente obtidos e o que ainda há de frágil na formação do professor de Língua Portuguesa que precisa ser vencido. Desse modo, apresentamos nossa segunda ponderação, que caminha no sentido de entender que análises documentais, sobre a formação docente, como a apresentada por este artigo, é somente a ponta de um "iceberg", que aponta para a necessidade de se entender o que se esconde por trás da aparente homogeneidade designativa que compõe as diretrizes para a formação do professor de Língua Portuguesa em nosso país.

\section{CONSIDERAÇÕES FINAIS}

Foram analisados os currículos de dez instituições de ensino superior de Minas Gerais que possuem o curso de Letras. A análise se deu especificamente a partir das ementas e dos programas de "Metodologia do Ensino de Língua Portuguesa" (MELP) oferecida nesses cursos.

Após análise das mesmas foi possível verificar que o estágio geralmente é ofertado nos períodos finais do curso, o que continua caracterizando a dicotomia entre teoria e prática como se os conhecimentos teóricos não pudessem congregarse às habilidades práticas que deveriam estar presentes em períodos subsequentes da formação.

Há uma gama variada de possibilidades de organização de $M E L P$, pois as temáticas presentes nas ementas, as cargas horárias, bem como o período de oferta variam consideravelmente. Assim, não é possível concluir que MELP, da forma como é ofertada nas instituições já citadas anteriormente, constitui a existência de um objeto específico que caracteriza o campo estudado, isso demonstra que o estudo realizado aponta para a necessidade de se compreender bem o que tem, atualmente, ocorrido neste grau de formação docente, avançando em pesquisas que alcancem discussões que problematizem as coincidências designativas, de modo que tenhamos condições efetivas de debater o que é hoje a formação do professor de Língua Portuguesa. 


\section{FABIANA OLIVEIRA}

Doutora em Educação pela Universidade Federal de São Carlos (UFSCar). Professora do Instituto de Ciências Humanas e Letras da Universidade Federal de Alfenas (UNIFAL-MG).

\section{DANIELA A. EUFRÁSIO}

Doutoranda em Educação pela Universidade de São Paulo (USP). Mestre em Educação pela USP. Professora do Instituto de Ciências Humanas e Letras da Universidade Federal de Alfenas (UNIFAL-MG).

\section{MARIA EMILIA A. DA C. TORRES}

Doutora em Linguística Aplicada pela Universidade Estadual de Campinas (UNICAMP). Professora do Instituto de Ciências e Tecnologia da Universidade Federal de Alfenas (UNIFAL-MG).

\section{REFERÊNCIAS}

BARZOTTO, V. H., BONFIM, N., SAMPAIO, M. L. P. Projeto de Cooperação Acadêmica: Disciplinas da Licenciatura voltadas para o ensino de Língua Portuguesa, 2008. Arquivo digital.

BRASIL. PARÂMETROS CURRICULARES NACIONAIS: Língua Portuguesa. Brasília: Secretaria de Educação Fundamental. SEF/MEC. 1995.

FOUCAULT, M. A ordem do discurso. São Paulo: Edições Loyola, 11 ed., 2004.

GERALDI, J. W., SILVA, L.L.M. \& FIAD, R. S. "Lingüística, Ensino de Língua Materna e Formação de Professores”. D.E.L.T.A., vol.12, nº 2, pp.307 -326, 1996.

GIMENO-SACRISTÁN, J. \& PÉREZ-GOMEZ, A. I. Compreender e transformar o ensino. Porto Alegre: Artmed, 1998.

GOMES, R. A análise de dados em pesquisa qualitativa. In: MINAYO, M. C. de S. Pesquisa social: teoria, método e criatividade. Petrópolis (RJ): Vozes, 1994. P.67-80.

ORLANDI, E. P. A produção da leitura e suas condições. In: BARZOTTO, Valdir H. Estado de Leitura. Campinas (SP): Mercado de Letras, 1999. p.47-59.

RIOLFI, C. R.; BAZON, F. V. M.; EUFRÁSIO, D. A.; PIETRI, E. Disciplinas da Licenciatura voltadas para 0 ensino de Língua Portuguesa: cooperação acadêmica entre UNIFAL-MG e USP, 2010. Arquivo digital. 